Revue d'histoire de l'Amérique française

REVUE D.HISTOIRE DE L'AMÉRIQUE FRANÇAISE

\title{
RICH, E.E. M.A., The History of the Hudson's Bay Company \\ (1670-1870). Volume 1 : 1670-1763. 687 p.
}

\section{Lionel Groulx}

Volume 12, numéro 4, mars 1959

URI : https://id.erudit.org/iderudit/301940ar

DOI : https://doi.org/10.7202/301940ar

Aller au sommaire du numéro

Éditeur(s)

Institut d'histoire de l'Amérique française

ISSN

0035-2357 (imprimé)

1492-1383 (numérique)

Découvrir la revue

Citer ce compte rendu

Groulx, L. (1959). Compte rendu de [RICH, E.E. M.A., The History of the Hudson's Bay Company (1670-1870). Volume 1 : 1670-1763. 687 p.]. Revue d'histoire de l'Amérique française, 12(4), 588-590. https://doi.org/10.7202/301940ar d'utilisation que vous pouvez consulter en ligne. 
RICH, E.E. M.A., The History of the Hudson's Bay Company 1670-1870 - Volume I: $1670-1763$, with a Foreword by the Right Honourable Sir Winston Churchill, K.G., O.M., C.H., F.R.S., M.P., Grand Seigneur of the Company of Adventurers of England trading into Hudson's Bay. Trois portraits : Prince Rupert, Charles II, Duc d'York. Cartes, en particulier, celle de Joseph Robson, 1752, où Robson situe, sur la Hayes, les forts de « Martiniere » et de Jean Chouart. Index. 687 pages.

Dans son «Foreword », Winston Churchill ne ménage pas les compliments à la célèbre Compagnie. De toutes les expéditions marchandes qui se sont envolées des Iles britanniques, dans les derniers quatre siècles et qui auraient influencé, modifié, dans l'ordre matériel, l'histoire des pays où elles ont abordé, nulle ne dépasserait en importance (none was more prominent) la Compagnie de la Baie d'Hudson. Son activité commerciale, née avec ses postes de traite, à l'époque où la fourrure constituait le principal article de commerce, s'est grossie, agrandie, jusqu'à ces vastes entreprises du 20 e siècle où la Compagnie aura si largement compté, dans le domaine de l'exploration et du développement matériel, au Canada. M. Churchill aper- 
çoit, dans le nom même de la Compagnie: The Adventurers of England Trading, l'esprit qui l'a toujours animée. Et il n'hésite pas à qualifier «epic » l'histoire de cette entreprise britannique.

La Compagnie de la Baie d'Hudson a conservé soigneusement ses archives: rapports, correspondances entre gouverneurs et Comité de Londres, journaux des postes. Elle n'a rien épargné pour les garder en bon état, les cataloguer, les mettre au service des historiens. De ces archives, la Hudson's Bay Record Society a déjà publié plusieurs volumes. Elle a jugé le temps venu de passer, de la documentation, à l'œuvre proprement historique. Cette histoire comprendra, pour le moment, deux volumes qui contiendront l'histoire de deux siècles. Début en mai 1670, avec l'octroi de la Charte royale; fin temporaire en 1870 , avec les grands changements survenus à l'époque, et dans la vie de la Compagnie et dans celle du Canada. Le premier volume de cette histoire s'enclôt en ces deux dates limites: 1670-1763. Il a pour auteur E. E. Rich, du St. Catharine's College de Cambridge, Vere Harmsworth Professor of Imperial and Naval History. Editeur de plusieurs volumes des archives de la Compagnie, nul n'était mieux qualifié que $M$. Rich. Nous espérons publier une étude plus soignée de ce premier volume de l'historien. En attendant, il importe, croyons-nous, de souligner, dans l'histoire du Canada, et particulièrement du Canada français, le rôle de la Compagnie de la Baie d'Hudson. Son commerce s'écoula, pendant longtemps, et pour une large part, en droiture de la Baie d'Hudson en Angleterre, sans beaucoup affecter, par son transit, la vie économique de la colonie. D'autre part, pendant le Régime français, la Compagnie demeura la suprême rivale des compagnies françaises dans le commerce des fourrures. Elle draina dangereusement de son côté les canots indiens et même ceux de la contrebande canadienne. Plus tard, sous le Régime britannique, elle devint la rivale inquiétante de la Compagnie canadienne du Nord-Ouest. Puis, la fusion accomplie entre les deux rivales, les canots de la Compagnie de la Baie d'Hudson apprirent le chemin des lacs et ceux de l'Outaouais et du SaintLaurent. On trouve la Compagnie mêlée aux premiers essais d'établissements dans l'actuel Manitoba. Ses postes de traite, dans l'Ouest du Canada et par delà les Rocheuses, formeront les premiers noyaux de la population blanche en chacune des actuelles provinces canadiennes de la région. Les mêmes postes, en dépit de quelques manifestations hostiles, serviront le plus souvent d'appui aux missions catholiques parmi les Indigènes. Chacun peut aussi évoquer le chapitre des explorations accomplies, dans le même temps, dans l'ouest de la grande baie, par delà les Rocheuses, jusqu'aux rives du Pacifique et de la mer glaciale. 
Soulignons également que le premier volume de cette histoire parue en 1958, s'apparente ou plutôt se lie largement à la période du Régime français en Nouvelle-France. On y trouvera le récit des relations de Groseilliers et de Radisson avec les 《 marchands aventuriers », les conquêtes ou expéditions du Chevalier de Troyes, celles d'Iberville à la Baie, tout le chapitre de la rivalité commerciale anglo-française, jusqu'au traité d'Utrecht, rivalité qui reprend et continue jusqu'à l'époque de La Vérendrye. Nul historien du Canada français ne peut donc ignorer cette histoire sortie des archives de la célèbre Compagnie à Londres.

LIONEL GROULX, ptre 